\title{
Strategi Pemasaran Pendidikan di MA Al Amiriyyah Blokagung Banyuwangi
}

\author{
Mamlukhah $^{1}$, Faiz Inayah ${ }^{2}$ \\ e-mail : mamlukhah@iaida.ac.id ${ }^{1}$, Fhafaa0198@gmail.com² \\ Prodi Manajemen Pendidikan Islam \\ Institut Agama Islam Darussalam Blokagung Banyuwangi
}

\begin{abstract}
This type of research is qualitative research. Qualitative research is a type of research whose findings are not obtained through statistical procedures or other forms of calculation. Qualitative research method is a type of purpose sampling research that is a non-random sampling technique where researchers determine the sampling by determining specific characteristics in accordance with the objectives of the researcher so that it is expected to answer the researcher's problems. So the researchers only need to take important points regarding sampling techniques and user indications. The purpose of this study was to find out how education marketing strategies in MA Al Amiriyyah Blokagung Tegalsari Banyuwangi, efforts in improving education marketing strategies in MA Al Amiriyyah Blokagung Tegalsari Banyuwangi, knowing the driving and inhibiting factors that influence the marketing strategy of MA Al Amiriyyah Blokagung Tegalsari Banyuwangi. Data analysis tools used in this study are interaction models, which consist of data display, data reduction, data collection, conclusion drawing and data verification. The research results obtained are the educational marketing marketing strategy matrix is a strategy of concentration through horizontal integration or stability (there is no change in earnings). With IE matrix (internal external) has an average of 2.50-3.00. With a total IFAS value of 3.00 and an EFAS value of 2.95. The conclusion in this study is the strategy used in education marketing which is divided into two short-term and long-term strategies, efforts to improve education marketing by marketing mix, the driving and inhibiting factors that influence education marketing strategies namely the existence of other educational institutions that are competitors and are the same area, and the feeling of not having a madrasah.
\end{abstract}

\section{Keywords: Strategic Marketing, Educational Marketing}

\begin{abstract}
Abstrak
Jenis penelitian ini adalah penelitian kualitatif. Penelitian kualitatif adalah jenis penelitian yang temuan-temuannya tidak diperoleh melalui prosedur statistik atau bentuk hitungan lainnya. Metode penelitian kualitatif adalah jenis penelitian purpose sampling yaitu teknik sampling non random dimana peneliti menentukan pengambilan sampel dengan cara menetapkan ciri-ciri khusus sesuai dengan tujuan peneliti sehingga di harapkan dapat menjawab permasalahan peneliti. Jadi peneliti cukup mengambil point-point penting perihal tentang teknik sampling serta indikasi penggunanya. Tujuan penelitian ini adalah mengetahui Bagaimana strategi pemasaran pendidikan di MA Al Amiriyyah Blokagung Tegalsari Banyuwangi, upaya dalam meningkatkan strategi pemasaran Strategi Pemasaran Pendidikan di MA Al Amiriyyah Blokagung Tegalsari Banyuwangi Mamlukhah, Faiz Inayah
\end{abstract}


pendidikan di MA Al Amiriyyah Blokagung Tegalsari Banyuwangi, mengetahui Faktor pendorong dan penghambat yang mempengaruhi strategi pemasaran pendidikan MA Al Amiriyyah Blokagung Tegalsari Banyuwangi. Analisisis data yang digunakan dalam penelitian ini adalah interaksi model yaitu yang terdiri dari Data display (penyajian data), Data reduction (reduksi data ), Data collection (pengumpulan data), penarikan kesimpulan dan verifikasi data. Hasil penelitian yang di peroleh adalah Matrik strategi pemasaran pemasaran pendidikan adalah strategi konsentrasi melalui integrasi horizontal atau stabilitas (tidak ada perubahan terhadap laba). Dengan matrik IE (internal eksternal) mempunyai rata-rata 2,50-3,00. Dengan total nilai IFAS adalah 3,00 dan nilai EFAS adalah 2,95. Kesimpulan dalam penelitian ini adalah strategi yang digunakan dalam pemasaran pendidikan yakni terbagi dua strategi jangka pendek dan jangka panjang, upaya untuk meningkatkan pemasaran pendidikan dengan cara bauran pemasaran, faktor pendorong dan pengahambat yang mempengaruhi strategi pemasaran pendidikan yakni adanya lembaga pedidikan lain yang menjadi pesaing dan berada di area yang sama, serta rasa tidak memilki madrasah.

\section{Kata Kunci: Strategi Pemasaran, Pemasaran Pendidikan}

\section{A. Pendahuluan}

\section{Latar Belakang Masalah}

Perkembangan ilmu pengetahuan dan teknologi menuntut masyarakat untuk melakukan perubahan sehingga mampu mengikuti perkembangan zaman. Di zaman yang modern ini persaingan dalam dunia pendidikan berkembang sangat pesat, untuk itu sangat penting bagi setiap masyarakat untuk meningkatkan kemampuan mengikuti persaingan yang kompetitif dalam krisis multidimensi. Pendidikan dipercaya menjadi alat untuk meningkatkan taraf hidup manusia. Dengan pendidikan, manusia menjadi cerdas, mempunyai skill, sikap hidup yang baik, sehingga mudah bergaul baik di masyarakat.

Menurut Undang-Undang Nomor. 20 Tahun 2003, tentang Sistem Pendidikan Nasional, BAB I Ketentuan Umum Pasal I Ayat I. Adalah usaha sadar dan terencana untuk mewujudkan suasana belajar dan proses pembelajaran agar peserta didik secara aktif mengembangkan potensi dirinya untuk memiliki kekuatan spiritual keeagamaan, pengendalian diri, kepribadian, kecerdasan akhlak mulia, serta keterampilan yang diperlukan dirinya, masyarakat, bangsa dan Negara. Sehubungan dengan hal tersebut 
dalam pemasaran dunia pendidikan, jasa layanan merupakan salah satu faktor penunjang terhadap minat masyarakat untuk menjadi pelanggan pendidikan. Semakin baik jasa yang ditawarkan, maka semakin tinggi pula terpenuhinya kebutuhan pelanggan tersebut. Istilah pemasaran dalam dunia pendidikan masih dianggap tabu karena pada umumnya pemasaran lebih banyak dikenal dalam dunia bisnis dan cenderung berorientasi pada laba. jasa pendidikan memegang peran penting untuk mengembangkan dan meningkatkan kualitas sumber daya manusia berbagai macam strategi dengan cara bauran promosi mereka lakukan untuk menarik minat peserta didik agar bersekolah ditempat mereka, dengan adanya persaingan ini maka sekolah memunculkan strategi pemasaran disekolah. Sekarang ini telah banyak muncul model-model Pendidikan dengan karakteristik yang berbeda beda. Seperti halnya di Darussalam ini ada tiga sekolah tingkat SLTA yakni SMA SMK dan MAA Pada dasarnya semuanya berupaya memasarkan program-program yang yang dimilki nya serta bertujuan untuk menarik minat siswa/i untuk masuk ke sebuah lembaga tersebut. dalam hal ini sangat penting adanya pemasaran dalam dunia pendidikan.

MA Al Amiriyyah Blokagung Banyuwangi mulai berdiri pada tanggal 07 April 1997 dibawah naungan Yayasan Pondok Pesantren Darussalam dengan lembaga induk Ma'arif, Status MA Al Amiriyyah terdaftar pada tanggal 24 Maret 1994 sampai tahun 2006 tetap dalam status "DIAKUI", pada tanggal 24 Agustus 2006 MA Al Amiriyyah Terakreditasi dengan nilai B (Baik). Dan sejak tanggal 19 November 2012 berubah menjadi Terakreditasi A. Saat ini MA Al Amiriyyah Blokagung memiliki 690 siswa, 45 jumlah personil yang terdiri dari guru, karyawan, dan petugas lainnya, 25 ruang kelas, 115 pelajaran, dan 8 extrakulikuler. Dilihat dari produk serta pelayanan baik dalam pemasaran pendidikan di MA Al Amiriyyah Blokagung tersebut telah banyak membawakan hasil yang sangat memuaskan baik untuk pihak sekolah, siswa maupun masyarakat yang menggunakan jasa Pemasaran Pendidikan. Untuk menyajikan keunggulan program Pendidikan serta pelayanan diperlukan Strategi Pemasaran Pendidikan di MA Al Amiriyyah Blokagung Tegalsari Banyuwangi 
beberapa strategi pemasaran yang bagi sekolah tersebut, baik dari produk yang dimiliki lembaga, dan sekolah sendiri juga harus bisa mengetahui dan menerapkan bahwasannya strategi tersebut tidak tertinggal dengan lembaga lain.

MA Al Amiriyyah Blokagung merupakan sekolah yang bernaungan Yayasan Pondok Pesantran Darusalam dimana sekolah ini berbasis kepesantrenan sehingga banyak masyarakat sekitar lebih mengunggulkan anak-anaknya untuk bisa mendapatkan didikan serta bimbingan yang baik dari segi agama maupun segi pengetahuan sosial dan pengetahuan alam, sesuai dengan program unggulan yang dimilki oleh sekolah. Sebanding dengan strategi Pemasaran Pendidikan sebaiknya juga harus di imbangi dengan kebutuhan masyarakat, dari hal itu lah tentunya sekolah tersebut juga tidak berdiri sendiri karena ada beberapa sekolah yang menjadi pesaing dengan memberikan kesan kualitas yang lebih unggul dan lebih diminati. Pemasaran dalam lembaga Pendidikan tersebut antara lain promosi sekolah lewat bener, sosialisasi langsung terhadap masyarakat sekitar, mengadakan baksos, lomba antar sekolah, beasiswa, juga menyajika ke unggulan dalam mengadakan extrakulikuler yang tidak dimiliki sekolahan yang lainya.

Lembaga Pendidikan MA Al Amiriyyah melakukan pemasaran dengan cara pendekatan langsung kepada walimurid dari hal tersebut memberikan beberapa pertanyaan yang perlu di kaji lebih mendalam terkait dengan startegi Pemasara Pendidikan di MA Al Amiriyyah. MA Al Amiriyyah tidak terlalu menonjolkan bagian promosi akan tetapi lebih mengunggulkan produk dalam dari sekolah itu sendiri Seperti menawarkan program kelas unggulan yakni program tahfidzul qur'an, bahasa dan pondok pesantren. Program tersebut diharapkan menjadi daya tarik para pelanggan pendidikan. Hal yang menarik adalah program-program yang ditawarkan merupakan program-program yang tidak ditawarkan di sekolah-sekolah lain, yaitu program tahfidz. MA Al-Amiriyyah telah banyak meraih juara di tingkat kecamatan, kabupaten dan provinsi. 
Jadi dari uraian latar belakang di atas penulis tertarik untuk meneliti. "Strategi Pemasaran Pendidikan Di MA Al Amiriyyah Blokagung Tegalsari Banyuwangi Tahun Pembelajaran 2019/2020”.

\section{Rumusan Masalah}

a. Bagaimana Strategi Pemasaran Pendidikan di MA Al Amiriyyah Blokagung Tegalsari Banyuwangi Tahun Pembelajaran 2019/2020?

b. Apa Faktor Pendorong dan Penghambat Dalam Meningkatkan Strategi Pemasaran Pendidikan di MA Al Amiriyyah Blokagung Tegalsari Banyuwangi Tahun Pembelajaran 2019/2020?

\section{Tujuan Penelitian}

a. Untuk Mengetahui Strategi Pemasaran Pendidikan Di MA Al Amiriyyah Blokagung Tegalsari Banyuwangi Tahun Pembelajaran 2019/2020.

b. Untuk Mengetahui Apa Faktor Pendorong Dan Penghambat Dalam Strategi Pemasaran Pendidikan di MA Al Amiriyyah Blokagung Tegalsari Banyuwangi Tahun Pembelajaran 2019/2020.

\section{Manfaat Penelitian}

Pada hakikatnya penelitian ini bertujuan untuk mendapatkan suatu manfaat. yaitu: manfaat teoritis dan manfaat praktis. Diantaranya:

a. Secara Teorotis

Untuk menambah wawasan keilmuan pemasaran pendidikan.

b. Secara Praktis

1. Bagi Kepala Sekolah

Diharapkan kepala sekolah dapat mengetahui proses pemasaran pendidikan

2. Bagi Sekolah

Penelitian ini diharapkan dapat membantu memberikan kontribusi untuk pengembangan sekolah di MA Al Amiriyyah terutama upaya untuk meningkatan strategi pemasaran pendidikan. 


\section{B. Landasan Teori}

\section{Strategi}

\section{a. Pengertian Strategi}

Istilah strategi berasal dari bahasa Yunani, yaitu Strategos (Stratos $=$ Militer dan Ag = Pemimpin), yang berarti Generalship atau sesuatu yang dikerjakan oleh para jenderal perang dalam membuat rencana untuk memenangkan perang. Definisi tersebut juga dikemukakan oleh seorang ahli bernama Clauswitz. Ia menyatakan bahwa strategi merupakan seni pertempuran untuk memenangkan perang. Oleh karena itu, tidak mengherankan apabila istilah strategi sering digunakan dalam kancah peperangan.Istilah strategi digunakan pertama kali di dunia militer.

Secara Harfiah, kata strategi dapat diartikan sebagai seni (Art Stratagem) yakni siasat atau rencana. Namun ada yang mengartikan strategi adalah tindakan potensial yang membuntuhkan keputusan manajemen tingkat atas dan sumber daya perusahaan dalam jumlah yang besar.Selain itu, strategi memengaruhi kemakmuran perusahaan dalam jangka panjang. Khususnya untuk lima tahun, dan berorientasi ke masa depan. Strategi memiliki konsekuensi yang multi fungsi dan multidimensi serta perlu mempertimbangkan faktor-faktor eksternal dan internal yang dihadapi perusahaan. Dari beberapa pengertian di atas dapat disimpulkan bahwa strategi adalah sebuah rencana atau program-program yang terencana untuk mencapai serangkaian tujuan yang telah ditentukan. Strategi yang digunakan dalam pendidikan biasanya berhubungan dengan rencana yang digunakan agar lebih efektif dan efisien dalam memasarkan sekolah.

\section{b. Proses Perencanaan Strategi}

strategi promosi merupakan rangkaian kegiatan yang dilakukan untuk menawarkan jasa atau pelayanan sekolah terhadap pelanggan, 
maka terdapat beberapa proses penyusunan strategi adalah seperti berikut :

1. Menentukan Misi dan Tujuan

2. Pengembangan Profil

3. Analisa Internal Perusahaan (Kekuatan Dan Kelemahan)

4. Analisa Lingkungan Eksternal (Peluang dan Ancaman)

5. Identivikasi Kesempatan Dan Ancaman Strategi

6. Pembuatan Keputusan Strategi

7. Pengembangan Strategi Perusahaan

8. Implementasi Strategi

9. Kembali dan Evaluasi

\section{Pemasaran Pendidikan}

\section{Pengertian Pemasaran Pendidikan}

Menurut Philip Kotler (1997: 8), "pemasaran adalah suatu proses sosial yang didalamnya individu dan kelompok mendapatkan apa yang mereka butuhkan dan inginkan dengan menciptakan, menawarkan, dan secara bebas mempertukarkan produk yang bernilai dengan pihak lain".

Pemasaran Jasa Pendidikan adalah kegiatan lembaga pendidikan memberi layanan atau penyampaian jasa pendidikan kepada konsumen dengan cara yang memuaskan (Buchari Alma, 2005: 75). Pemasaran adalah suatu proses sosial dan manajerial yang melibatkan kegiatan-kegiatan penting yang memungkinkan individu dan kelompok mendapatkan kebutuhan dan keinginan melalui pertukaran dengan pihak lain.

Berdasarkan beberapa pengertian pemasaran pendidikan di atas dapat disimpulkan bahwa pemasaran adalah suatu proses kegiatan usaha untuk memenuhi kebutuhan konsumen dengan cara menciptakan dan menawarkan produknya yang akan di pasarkan.

\section{a. Bauran Pemasaran (Marketing Mix)}


Menurut Kotler dan Fox menyatakan bahwa pemasaran jasa pendidikan akan menawarkan jasa pendidikan dengan bauran pemasaran yang terdiri atas tujuh alat yakni 7P diantaranya terdiri dari: Product, Prince, Promotion, People, Physical Evidence, Process.

\section{b. Bauran Promosi (Marketing Mix)}

Menurut Swasta dan Irawan (2005: 347), "bauran promosi adalah kombinasi strategi yang paling baik dari variabel-variabel periklanan, personal selling, dan alat promosi yang lain, yang semuanya direncanakan untuk mencapai tujuan program penjualan. Bauran promosi merupakan alat-alat yang digunakan dalam promosi yang terdiri dari periklanan, promosi penjualan dan pemasaran langsung. Adapun beberapa jenis-jenis bauran promosi yaitu: Periklanan (Advertising), Penjualan Pribadi (Personal Selling), Promosi Penjualan (Sales Promotion), Publishing (Puublicity).

\section{Penelitian Terdahulu}

Beberapa penelitian terdahulu yang berhubungan dengan penelitian ini dan dijadikan pembanding bagi penelitian ini adalah sebagai berikut:

\begin{tabular}{|c|c|c|c|c|c|c|}
\hline No & $\begin{array}{c}\text { Nama } \\
\text { dan } \\
\text { Tahun }\end{array}$ & Judul & $\begin{array}{c}\text { Metode } \\
\text { Penelitian }\end{array}$ & Hasil & Persamaan & Perbedaan \\
\hline 1. & $\begin{array}{l}\text { Lili } \\
\text { Amalia } \\
(2017)\end{array}$ & $\begin{array}{l}\text { Strategi } \\
\text { Pemasaran Jasa } \\
\text { Pendidikan Di } \\
\text { SMP Harapan } \\
\text { Baru Bekasi }\end{array}$ & $\begin{array}{l}\text { Metode } \\
\text { yang di } \\
\text { gunakan } \\
\text { kualitatif }\end{array}$ & $\begin{array}{l}\text { Sudah } \\
\text { dilaksanakan } \\
\text { dengan baik } \\
\text { tetapi akan } \\
\text { lebih baik } \\
\text { lagi jika } \\
\text { dalam } \\
\text { kegiatan } \\
\text { promosi } \\
\text { dapat } \\
\text { terdokumen } \\
\text { dengan rapi. }\end{array}$ & $\begin{array}{l}\text { Sama - sama } \\
\text { meneliti } \\
\text { strategi } \\
\text { pemasaran } \\
\text { pendidikan }\end{array}$ & $\begin{array}{l}\text { Yang di teliti } \\
\text { berbeda, } \\
\text { objeknya } \\
\text { berbeda, } \\
\text { Kata kunci } \\
\text { yang dituju } \\
\text { berbeda }\end{array}$ \\
\hline
\end{tabular}




\begin{tabular}{|c|c|c|c|c|c|c|}
\hline 2. & $\begin{array}{l}\text { Aditia } \\
\text { Fradito } \\
(2016)\end{array}$ & $\begin{array}{l}\text { Strategi } \\
\text { Pemasaran } \\
\text { Pendidikan } \\
\text { Dalam } \\
\text { Meningkatkan } \\
\text { Citra Lembaga } \\
\text { Pendidikan"(Stu } \\
\text { di Multikasus } \\
\text { Di SDI Surya } \\
\text { Buana Dan Min } \\
\text { Malang 2) } \\
\text { Tahun 2016. }\end{array}$ & $\begin{array}{l}\text { Metode } \\
\text { penelitian } \\
\text { mengguna } \\
\text { kan } \\
\text { deskriptif } \\
\text { kualiatatif }\end{array}$ & $\begin{array}{l}\text { Sudah } \\
\text { berjalan } \\
\text { dengan baik } \\
\text { dapat dilihat } \\
\text { terjalinnya } \\
\text { kerja sama } \\
\text { yang efektif } \\
\text { antar } \\
\text { sekolah dan } \\
\text { orang tua } \\
\text { siswa. }\end{array}$ & $\begin{array}{l}\text { Sama - sama } \\
\text { meneliti } \\
\text { strategi } \\
\text { pemasaran } \\
\text { pendidikan }\end{array}$ & $\begin{array}{l}\text { Yang di teliti } \\
\text { berbeda } \\
\text { serta } \\
\text { analisis data } \\
\text { yang } \\
\text { digunakan } \\
\text { berbeda }\end{array}$ \\
\hline 3. & $\begin{array}{l}\text { Galisa } \\
\text { Ayu } \\
\text { Famela } \\
(2019)\end{array}$ & $\begin{array}{l}\text { Implementasi } \\
\text { Strategi } \\
\text { Pemasaran } \\
\text { Pendidikan } \\
\text { (Studi Kasus Di } \\
\text { MTs Negeri } 2 \\
\text { Bandar } \\
\text { Lampung) } \\
\text { Tahun 2019. }\end{array}$ & $\begin{array}{l}\text { Metode } \\
\text { penelitian } \\
\text { mengguna } \\
\text { kan } \\
\text { deskriptif } \\
\text { kualiatatif }\end{array}$ & $\begin{array}{l}\text { Sangat baik } \\
\text { meliputi } \\
\text { produk, } \\
\text { price,place,p } \\
\text { romotion,pe } \\
\text { ople, } \\
\text { physical,pro } \\
\text { cess }\end{array}$ & $\begin{array}{l}\text { Sama - sama } \\
\text { meneliti } \\
\text { strategi } \\
\text { pemasaran } \\
\text { pemdididkan }\end{array}$ & $\begin{array}{l}\text { Yang di teliti } \\
\text { berbeda, } \\
\text { objeknya } \\
\text { berbeda, } \\
\text { Kata kunci } \\
\text { yang dituju } \\
\text { berbeda }\end{array}$ \\
\hline
\end{tabular}

Sumber Data : Olahan Peneliti 2020

\section{Metode Penelitian}

\section{Jenis Penelitian}

Penelitian ini menggunakan pendekatan kualitatif yang mendiskripsikan tentang strategi pemasaran pendidikan di MA Al Amiriyyah Blokagung secara apa adanya.

\section{Lokasi Penelitian}

Lokasi penelitian di MA Al Amiriyyah Blokagung Banyuwangi.

\section{Sumber Data}

Sumber data yang digunakan dalam penelitian ini ada dua yaitu: sumber data primer dan sekunder. Sumber data primer adalah sumber data yang dipakai peneliti dalam menghimpun data utama yakni pengelola MA Al Amiriyyah sebagai narasumber utama dan observasi langsung dilembaga untuk mendapatkan data berupa kondisi nyata masalah penelitian. sedangkan sumber data sekunder diperoleh dari bagian tata 
usaha untuk mendapatkan data data terkait administrasi dan data pendukung penelitian lainnya.

\section{Teknik Pengumpulan Data}

Data penelitian ini dikumpulkan melalui beberapa teknik, yaitu wawancara, observasi, dan dokumentasi.

\section{Teknik Analisis Data}

Analisis data dalam penelitian ini menggunakan analisis SWOT ( strengts, weakness, opportunities, and threats)

\section{E. Hasil Penelitian}

Dari hasil observasi serta wawancara yang dilaksanakan oleh peneliti diperoleh hasil temuan penelitian.

\begin{tabular}{|c|c|}
\hline Rumusan Masalah & Temuan penelitian \\
\hline $\begin{array}{c}\text { Strategi Pemasaran } \\
\text { Pendidikan di MA Al } \\
\text { Amiriyyah }\end{array}$ & $\begin{array}{l}\text { a. Bauran Pemasaran } \\
\text { b. Bauran Promosi }\end{array}$ \\
\hline $\begin{array}{l}\text { Bauran Pemasaran } \\
\text { (7p) Yang Meliputi: } \\
\text { Produk, Price, Place, } \\
\text { Physical Evidence, } \\
\text { Promotion, Proses. }\end{array}$ & $\begin{array}{l}\text { 1. Produk intratkulikuler, ekstrakulikuler, keagamaan, serta } \\
\text { produk unggulan IPA,IPS dan agama. keunggulan produk } \\
\text { yang dimiliki yakni program ipa dan tahfidzul qur'an. } \\
\text { Kelemahan produk tersebut yakni kebayakan siswa/i yang } \\
\text { berprestasi tersebut yakni santri pondok pesantren sehingga } \\
\text { jika mereka sudah lulus sekolah akan kembali kerumahnya } \\
\text { dan akan sulit untuk mencari kader-kader baru. } \\
\text { 2. Price diambil dari prestasi siswa. Untuk juara } 1 \text { tingkat } \\
\text { kabupaten gratis SPP } 1 \text { semester, juara } 1 \text { tingak provinsi } \\
\text { gratis SPP } 1 \text { tahun, untuk juara } 2 \text { gratis LKS. Kelebihan } \\
\text { memiliki } 2 \text { standar harga yakni reguler dan non reguler. } \\
\text { Kelemahannya, wali siswa tidak bisa nyicil untuk } \\
\text { pembayaran. Karena pembiayaan digabung menjadi satu. } \\
\text { 3. Place. kekuatan yang dimiliki sekolah yakni lokasi sekolah } \\
\text { yang berada dipondok terbesar se banyuwangi, } \\
\text { kekurangannya yakni jauh dari pusat kota serta vasilitas } \\
\text { publik. } \\
\text { 4. Promosi media internet melalui WA, FB, website, siaran } \\
\text { radio, media cetak dengan menyebar brosur, dan memasang } \\
\text { spanduk. Serta mengadakan ivent tertentu. Kelemahannya } \\
\text { tidak dapat menjangkau luar daerah, kurang waktu dan } \\
\text { biaya tenaga, mahalnya biaya untuk iklan. } \\
\text { 5. Bukti fisik yang dimiliki sekolah yakni sarana prasarana yang } \\
\text { memadai pelayanan yang 98\% baik. kelemahan yang } \\
\text { dimiliki adanya wali siswa yang tidak bisa dijangkau untuk } \\
\text { memberikan informasi tentang anaknya. } \\
\text { 6. People memiliki tim khusus yang di sebut PSPBB yang } \\
\text { berfungsi untuk hal pemasaran pendidikan yang didorong } \\
\text { oleh wakil kepala madrasah. Kelemahanyang dimiliki pihak }\end{array}$ \\
\hline
\end{tabular}




\begin{tabular}{|c|c|}
\hline & $\begin{array}{l}\text { sekolah masih bernaungan dan ikut pada yayasan, belum } \\
\text { bisa mendirikan sendiri. } \\
\text { 7. Proses dalam pemasrakan pendidikan tentunya tidak selalu } \\
\text { lancar, bagus dan sesuai dengan rancangan dan tujuan yang } \\
\text { di inginkan, akan tetapi berjalan dengan bertahap awalnya } \\
\text { proses pemasaran masih dalam lingkup yang sempit karena } \\
\text { tuntutan perkembangan zaman akhirnya pihak sekolah } \\
\text { menciptakan inovasi baru dan menjadikan proses tersebut } \\
\text { menjadi berkembang. }\end{array}$ \\
\hline Bauran Promosi & $\begin{array}{l}\text { 1. Audien yang menjadi sasaran yakni SMP dan SMA di } \\
\text { darussalam untuk tingkat dalam, untuk tingkat luar yakni } \\
\text { MA Unggulan Mambaul Huda. } \\
\text { 2. Anggaran yang ditentukan meliputi biaya SPP dan reward } \\
\text { bagi anak didik yang mendapatkan prestasi diantaranya } \\
\text { gratis biaya SPP dan LKS. } \\
\text { 3. Saluran komunikasi yang digunakan MA Al Amiriyyah yakni } \\
\text { saluran komunikasi langsung dan tidak langsung, } \\
\text { komunikasi langsung dengan cara membentuk tim khusus } \\
\text { yang dinamakan PSDPDB khusus untuk bagian pemasaran } \\
\text { dan penerimaan peserta ccicik baru juga dibantu oleh guru, } \\
\text { TU dan WAKA Humas, komunikasi tidak langsung dengan } \\
\text { cara menyampaikan pesan yang berupa profil sekolah } \\
\text { melalui pesan media internet, acara tertentu seperti Haul dan } \\
\text { lain-lain. }\end{array}$ \\
\hline $\begin{array}{lr}\text { Faktor } & \text { Pendorong } \\
\text { Dan } & \text { Penghambat } \\
\text { dalam } & \text { Strategi } \\
\text { Pemasaran } & \\
\text { Pendidikan di MA Al } & \text { Amiriyyah } \\
\text { Blokagung }\end{array}$ & $\begin{array}{l}\text { a. bauran pemasaran } \\
\text { b. bauran promosi }\end{array}$ \\
\hline $\begin{array}{l}\text { a. Faktor Pendorong } \\
\text { Dan Penghambat } \\
\text { Bauran } \\
\text { Pemasaran }\end{array}$ & $\begin{array}{l}\text { 1. Produk di lembaga MA Al Amiriyyah, adapun faktor } \\
\text { pendorong yang meliputi program unggulan tahfidz yang } \\
\text { jarang dimiliki oleh lembaga lain, siswa yang memiliki } \\
\text { bekal prestasi dari pondok dan sekolahtinggal } \\
\text { mengebangkannya saja. Untuk faktor penghambat yang } \\
\text { dimiliki lembaga terkait produk yakni siswa yang berada } \\
\text { pada naungan pondok pesantren tidak bisa menciptakan } \\
\text { kader-kader baru. } \\
\text { 2. Penetapan biaya pendidikan yang menjadi faktor pendorong } \\
\text { yakni anggaran biaya pendidikan di MA Al Amiriyyah } \\
\text { disesuaikan dengan tingkat kelas, dan fasilitas yang diperoh } \\
\text { siswa, serta pihak sekolah memberikan reward bagi siswa } \\
\text { yang berprestasi. Untuk faktor penghambat yang dimiliki } \\
\text { yakni keberatan wali siswa akan penetapan biaya } \\
\text { pendidikan yang digabung dengan biaya pondok pesantren } \\
\text { akibatnya wali siswa tidak bisa nyicil untuk melunasinya. } \\
\text { Untuk faktor pendorong terkait lokasi yang dimiliki oleh } \\
\text { lembaga yakni lembaga bertempat di yayasan pondok } \\
\text { pesantren terbesar di BWI, adapun faktor penghambat yang }\end{array}$ \\
\hline
\end{tabular}




\begin{tabular}{|c|c|}
\hline & $\begin{array}{l}\text { dimiliki lembaga yakni jika lembaga tidak bernaungan } \\
\text { pondok pesantren maka lembaga akan mati. } \\
\text { 4. Faktor pendorong promosi terkait pemasaran pendidikan } \\
\text { yakni promosi dapat diperoleh dengan banyak cara sesuai } \\
\text { dengan perkembangan teknologi yang mengharuskan } \\
\text { lembaga untuk berkembang. Untuk faktor penghambatnya } \\
\text { yakni tidak bisa menjangkau promosi luar daerah hanya } \\
\text { lewat siswa saja. } \\
\text { 5. Faktor pendorong dari bukti fisik yang dimiliki lembaga } \\
\text { yakni memiliki seluruh kegiatan ekstra sarana dan ada } \\
\text { produknya. Untuk faktor penghambatnya yakni sulitnya } \\
\text { menjangkau wali siswa yang tidak memiliki aplikasi WA } \\
\text { sehingga susah untuk memberikan informasi terkait } \\
\text { anaknya. } \\
\text { Orang yang terlibat dalam pemasaran pendidikan yakni } \\
\text { seluruh guru, siswa, staff yang ada dilembaga tersebut. } \\
\text { Faktor penghambatnya yakni sekolah belum bisa } \\
\text { mendirikan PSBDB sendiri akan tetapi masih ikut dengan } \\
\text { yayasan. } \\
\text { 7. Proses yang menjadi faktor pendorong yakni sekolah bisa } \\
\text { berkembang lebih baik karena tuntuan zaman yang semakin } \\
\text { modern. }\end{array}$ \\
\hline $\begin{array}{l}\text { b. Faktor Pendorong } \\
\text { Dan Penghambat } \\
\text { Bauran Promosi. }\end{array}$ & $\begin{array}{l}\text { 1. Peluang lebih mudah dijangkau karena audien sasarannya } \\
\text { berada dilokasi yang sama. Untuk ancamannya yakni ada } \\
\text { sekolah yang menjadi pesaing yakni SMA dan SMK } \\
\text { darussalam karena berada diarea yang sama. } \\
\text { 2. Ancaman yang diperoleh dari peluang tersebut yakni adanya } \\
\text { pesaing lain yang menawarkan biaya pendidikan lebih } \\
\text { murah. } \\
\text { 3. Peluang yang diperoleh yakni memperkuat hubungan baik } \\
\text { dengan masyarakat, sedangkan ancaman yang diperoleh } \\
\text { yakni adanya pesaing yang lebih kompeten dalam menjalin } \\
\text { hubungan baik dengan masyarakat. }\end{array}$ \\
\hline
\end{tabular}

\section{F. Pembahasan}

\section{Matrik Analisis Strategi Pemasaran Pendidikan di MA Al Amiriyyah Blokagung Tegalsari Banyuwangi Tahun Pembelajaran 2019/2020}

Penelitian ini dilakukan di MA Al Amiriyyah Blokagung dengan narasumber Bapak Abdul Wahid Amiruddin SH. sebagai guru serta kepala bidang pemasaran pendidikan serta WAKA Humas di MA Al Amiriyyah Blokagung. Penelitian ini menggunakan metode kualitatif dengan menggunakan analisis SWOT.

\section{a. Analisis SWOT}

Berdasarkan pengamatan penelitian, dari hasil wawancara pihakpihak terkait maka diperoleh analisis SWOT nya adalah: 


\section{1) Analisis Internal Madrasah}

Strength (kekuatan) adalah memiliki citra yang positif dibawah naungan pondok pesantren, menjadi madrasah swasta terbesar di BWI, SDM yang cukup baik, sarana prasarana yang memadai dan memiliki kualitas prestasi yang diraih. Weakness (kelemahan) adalah letak sekolah yang jauh dari pusat kota, dan jauh dari vasilitas publik, rasa tidak memiliki madrasah, keterbatasan biaya, waktu dan tenaga, output tidak bisa menciptakan kader-kader baru.

Tabel IFAS (Internal Strategic Faktocrs Analysis Summary)

\begin{tabular}{|c|c|c|c|c|}
\hline $\begin{array}{c}\text { FAKTOR STRATEGI } \\
\text { INTERNAL }\end{array}$ & $\begin{array}{l}\text { BOBOT } \\
\text { (A) }\end{array}$ & $\begin{array}{l}\text { RATING } \\
\text { (B) }\end{array}$ & $\begin{array}{l}\text { SKOR } \\
(\mathbf{A x B})\end{array}$ & KETERANGAN \\
\hline $\begin{array}{l}\text { Kekuatan: } \\
\text { - } \quad \text { Memiliki citra positif } \\
\text { dibawah naungan } \\
\text { pondok pesantren } \\
\text { terbesar di BWI }\end{array}$ & 0,15 & 4 & 0,60 & $\begin{array}{l}\text { Bobot } 0,15 \text { dengan rating } 4 \\
\text { sangat penting menjadi } \\
\text { kekuatan MAA }\end{array}$ \\
\hline $\begin{array}{l}\text { - } \text { Menjadi madrasah } \\
\text { terbesar di BWI }\end{array}$ & 0,15 & 3 & 0,45 & $\begin{array}{l}\text { Bobot } 0,15 \text { dengan rating } 2 \\
\text { baik menjadi kekuatan MAA }\end{array}$ \\
\hline - $\quad$ SDM yang cukup baik & 0,15 & 3 & 0,45 & $\begin{array}{l}\text { Bobot } 0,15 \text { dengan rating } 3 \\
\text { sangat baik menjadi } \\
\text { kekuatan MAA }\end{array}$ \\
\hline $\begin{array}{l}\text { - Sarana dan prasarana } \\
\text { yang memadai }\end{array}$ & 0,15 & 4 & 0,60 & $\begin{array}{l}\text { Bobot } 0,15 \text { dengan rating } 4 \\
\text { sangat penting menjadi } \\
\text { kekuatan MAA }\end{array}$ \\
\hline $\begin{array}{ll}\text { - } & \text { Memiliki kualitas } \\
& \text { prestasi yang diraih }\end{array}$ & 0,15 & 2 & 0,30 & $\begin{array}{l}\text { Bobot } 0,15 \text { dengan rating } 2 \\
\text { baik menjadi kekuatan MAA }\end{array}$ \\
\hline $\begin{array}{l}\text { Kelemahan: } \\
\text { - Letak sekolah yang } \\
\text { jauh dari pusat kota } \\
\text { dan jauh dari vasilitas } \\
\text { publik }\end{array}$ & 0,05 & 2 & 0,10 & $\begin{array}{l}\text { Bobot } 0,05 \text { dengan rating } 1 \\
\text { menjadi kelemahan MAA }\end{array}$ \\
\hline $\begin{array}{lr}\text { - } & \text { Sulit menjangkau } \\
\text { promosi di luar daerah } \\
\text { karena kurangnya }\end{array}$ & 0,10 & 1 & 0,10 & $\begin{array}{l}\text { Bobot } 0,10 \text { dengan rating } 1 \\
\text { tidak penting kelemahan } \\
\text { MAA }\end{array}$ \\
\hline
\end{tabular}

Strategi Pemasaran Pendidikan di MA Al Amiriyyah Blokagung Tegalsari Banyuwangi 


\begin{tabular}{|l|l|l|l|l|}
\hline $\begin{array}{l}\text { waktu, biaya dan } \\
\text { tenaga }\end{array}$ & & & & \\
\hline $\begin{array}{l}\text { Rasa tidak memiliki } \\
\text { madrasah }\end{array}$ & 0,05 & 1 & 0,20 & $\begin{array}{l}\text { Bobot 0,05 dengan rating 1 } \\
\text { menjadi kelemahan MAA }\end{array}$ \\
\hline $\begin{array}{l}\text { Output tidak bisa } \\
\text { menciptakan kader- } \\
\text { kader baru }\end{array}$ & 0,15 & 2 & 0,10 & $\begin{array}{l}\text { Bobot 0,30 dengan rating 2 } \\
\text { sangat tidak penting menjadi } \\
\text { kelemahan MAA }\end{array}$ \\
\hline $\begin{array}{l}\text { Keberatan wali murid } \\
\text { dengan penggabungan } \\
\text { biaya SPP }\end{array}$ & 0,10 & 2 & 0,10 & $\begin{array}{l}\text { Bobot 0,20 tidak penting } \\
\text { menjadi kelemahan MAA }\end{array}$ \\
\hline TOTAL & & & $\mathbf{3 , 0 0}$ & \\
\hline
\end{tabular}

Sumber: Data Olahan Peneliti Tahun 2020

\section{2) Analisis Eksternal Madrasah}

Oppourtinities (Peluang) adalah banyaknya pihak konsumen yang tertarik dengan MA Al Amiriyyah Blokagung karena yayasan yang berbasis pesantren, juga produk unggulan yang dimiliki yakni program IPA, IPS, dan Agama kini menjadi kebutuhan dalam pendidikan anak, khususnya program tahfidz yang ada di MA Al Amiriyyah Blokagung yang jarang dimiliki oleh lembaga lain, membuka brosur tentang perstasi yang diraih oleh MA Al Amiriyyah Blokagung menjalin komunikasi yang baik terhadap audien sasaran, mengadakan acara tertentu untuk menyampaikan pesan provil sekolah. Thearts (ancaman) adanya lembaga pendidikan lain yang menjadi pesaing diarea yang sama, persaingan harga serta kualitas dengan lembaga pendidikan lain, lembaga lain mampu mengeluarkan output yang lebih inovatif dan kreatif, pesaing yang menawarkan harga murah, pesaing yang memiliki kapasitas yang lebih besar.

Tabel EFAS (Eksternal Strategic Faktocrs Analysis Summary)

\begin{tabular}{|c|c|c|c|ccc|}
\hline $\begin{array}{c}\text { FAKTOR STRATEGI } \\
\text { EKSTERNAL }\end{array}$ & $\begin{array}{c}\text { BOBOT } \\
(\mathbf{A})\end{array}$ & $\begin{array}{c}\text { RATING } \\
(\mathbf{B})\end{array}$ & $\begin{array}{c}\text { SKOR } \\
(\mathbf{A x B})\end{array}$ & \multicolumn{2}{|c|}{ KETERANGAN } & \\
\hline Peluang: & 0,15 & 4 & 0,60 & Bobot & 0,15 & dengan \\
\hline
\end{tabular}

Strategi Pemasaran Pendidikan di MA Al Amiriyyah Blokagung Tegalsari Banyuwangi 


\begin{tabular}{|c|c|c|c|c|}
\hline 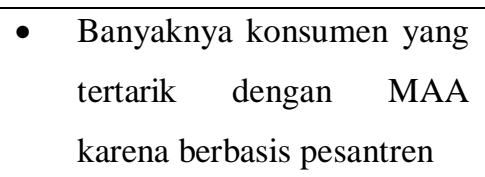 & & & & $\begin{array}{l}\text { rating } 4 \text { sangat penting } \\
\text { menjadi peluang besar } \\
\text { MAA }\end{array}$ \\
\hline 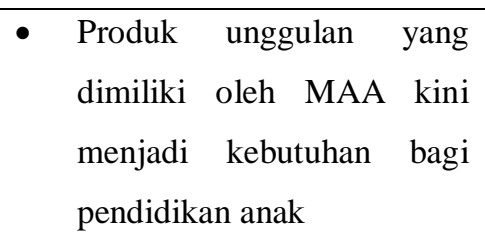 & 0,15 & 4 & 0,60 & $\begin{array}{l}\text { Bobot } 0,15 \text { dengan } \\
\text { rating } 4 \text { sangat penting } \\
\text { menjadi peluang MAA }\end{array}$ \\
\hline 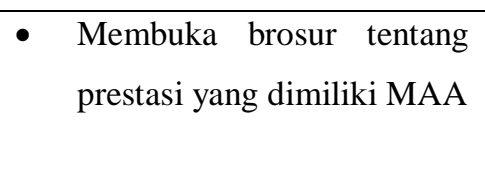 & 0,15 & 2 & 0,30 & $\begin{array}{l}\text { Bobot } 0,15 \text { dengan } \\
\text { rating } 2 \text { baik menjadi } \\
\text { peluang } \\
\text { MAA }\end{array}$ \\
\hline $\begin{array}{l}\text { - Menjalin komunikasi yang } \\
\text { baik terhadap audien } \\
\text { sasaran }\end{array}$ & 0,15 & 2 & 0,30 & $\begin{array}{lrr}\text { Bobot } 0,15 & \text { dengan } \\
\text { rating } 2 \text { baik } & \text { menjadi } \\
\text { peluang } & \text { MAA }\end{array}$ \\
\hline $\begin{array}{lr}\text { - } & \text { Mengadakan pertemuan } \\
\text { tertentu dengan } & \text { audien } \\
\text { sasaran } & \text { untuk } \\
\text { menyampaikan } & \text { provil } \\
\text { sekolah } & \end{array}$ & 0,15 & 2 & 0,30 & $\begin{array}{l}\text { Bobot } 0,15 \text { dengan } \\
\text { rating } 2 \text { baik menjadi } \\
\text { peluang MAA }\end{array}$ \\
\hline $\begin{array}{l}\text { Ancaman: } \\
\text { - } \quad \text { Adanya lembaga } \\
\text { pendidikan lain yang } \\
\text { menjadi pesaing diarea } \\
\text { yang sama. }\end{array}$ & 0,05 & 1 & 0,05 & $\begin{array}{lcr}\text { Bobot } & 0,05 & \text { dengan } \\
\text { rating } & 1 & \text { menjadi } \\
\text { ancaman MAA } & \end{array}$ \\
\hline 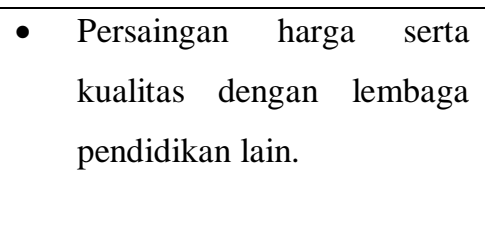 & 0,10 & 2 & 0,20 & $\begin{array}{lrr}\text { Bobot } & 0,10 & \text { dengan } \\
\text { rating } & 2 & \text { sangat } \\
\text { pentidak } & \text { menjadi } \\
\text { ancaman MAA }\end{array}$ \\
\hline 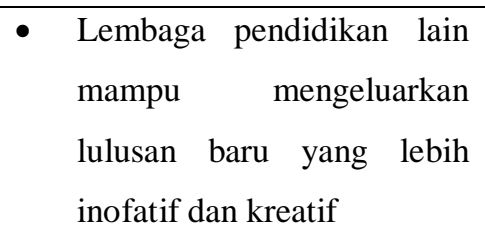 & 0,10 & 2 & 0,20 & $\begin{array}{lrr}\text { Bobot } & 0,10 & \text { dengan } \\
\text { rating } 2 & \text { sangat tidak } \\
\text { penting } & \text { menjadi } \\
\text { ancaman MAA }\end{array}$ \\
\hline $\begin{array}{l}\text { - Pesaing yang menawarkan } \\
\text { harga murah }\end{array}$ & 0,05 & 1 & 0,05 & $\begin{array}{lcr}\text { Bobot } & 0,05 & \text { dengan } \\
\text { rating } & 1 & \text { menjadi } \\
\text { ancaman } & \text { MAA }\end{array}$ \\
\hline $\begin{array}{l}\text { Pesaing yang memiliki } \\
\text { kapasitas yang lebih besar }\end{array}$ & 0,10 & 2 & 0,20 & $\begin{array}{l}\text { Bobot } 0,10 \text { dengan } \\
\text { rating } 2 \text { sangat tidak }\end{array}$ \\
\hline
\end{tabular}

Strategi Pemasaran Pendidikan di MA Al Amiriyyah Blokagung Tegalsari Banyuwangi 


\begin{tabular}{|c|l|l|l|l|}
\hline & & & & $\begin{array}{l}\text { penting menjadi } \\
\text { ancaman MAA }\end{array}$ \\
\hline TOTAL & & & $\mathbf{2 9 5}$ & \\
\hline
\end{tabular}

Sumber: Data Olahan Peneliti (2020)

\section{3) Matrik IE (Internal Eksternal)}

Pada matrik IE, analisis menempatkan analisis internal MA Al Amiriyyah dalam kondisi kuat yaitu 3,00-4,00. Dan analisis eksternal pada kondisi sedang yaitu antara nilai 2,50-3,00. MA Al Amiriyyah Blokagung berada dalam sel 4 yakni hold and build karena total nilai dari matrik IFAS adalah 3,00 dan total nilai EFAS adalah 2,95 yang berarti MA Al Amiriyyah Blokagung berada dalam strategi konsentrasi melalui integrasi horizontal atau stabilitas (tidak ada perubahan terhadap laba).

Pada matrik IFAS dapat dilihat bahwa pemasaran memiliki kualitas prestasi yang diraih menjadi madrasah swasta terbesar di BWI, SDM yang cukup baik, memiliki citra yang positif dibawah naungan pondok pesantren, sarana prasarana yang memadai masingmasing mempunyai bobot 0,15 menjadi kekuatan yang besar bagi MA Al Amiriyyah Blokagung untuk terus berjalan dan menghadapi persaingan. Sedangkan MA Al Amiriyyah Blokagung pemasarannya yang keterbatasan biaya, waktu dan tenaga, output tidak bisa menciptakan kader-kader baru, letak sekolah yang jauh dari pusat kota, jauh dari vasilitas publik, rasa tidak memiliki madrasah merupakan kelemahan terbesar yang dimiliki MA Al Amiriyyah Blokagung yang memiliki bobot masing-masing 0,05 yang harus dihadapi dengan kekuatan dan peluang yang ada, agar menarik konsumen untuk mau menyekolahkan anaknya di lembaga pendidikan MA Al Amiriyyah Blokagung ini.

Pada matrik EFAS adalah membuka brosur tentang perstasi yang diraih oleh MA Al Amiriyyah Blokagung, menjalin komunikasi yang baik terhadap audien sasaran, mengadakan acara tertentu untuk 
menyampaikan pesan provil sekolah. banyaknya konsumen yang tertarik dengan MA Al Amiriyyah Blokagung karena berbasis pesantren, produk unggulan yang dimiliki MA Al Amiriyyah Blokagung kini menjadi kebutuhan dalam pendidikan anak merupakan peluang besar MA Al Amiriyyah Blokagung agar dapat berjalan lancar dengan bobot 0,15 . Adanya lembaga pendidikan lain yang menjadi pesaing diarea yang sama merupakan ancaman yang harus dihadapi bagi MA Al Amiriyyah Blokagung dengan kekuatan dan peluang agar lebih memilih bergabung di MA Al Amiriyyah Blokagung dengan produk unggulan tahfidz yang tidak dimiliki di lembaga lain yang mempunyai bobot masing-masih 0,05 .

Tabel Penentuan Strategi Matrik IE (Internal Eksternal)

\begin{tabular}{|c|c|c|}
\hline INTERNAL FAKTOR & $\begin{array}{l}\text { Kekuatan (Srength) } \\
\text { - } \text { Memiliki citra positif } \\
\text { dibawah naungan pondok } \\
\text { pesantren terbesar di BWI } \\
\text { - } \text { Menjadi madrasah swasta } \\
\text { terbesar di BWI } \\
\text { - SDM yang cukup baik } \\
\text { - } \text { Sarana dan prasarana yang } \\
\text { memadai } \\
\text { Memiliki kualitas prestasi } \\
\text { yang diraih }\end{array}$ & $\begin{array}{l}\text { Kelemahan (Weaknes) } \\
\text { - } \quad \text { Letak sekolah yang jauh } \\
\text { dari pusat kota dan jauh } \\
\text { dari vasilitas publik. } \\
\text { - Sulit menjangkau } \\
\text { promosi di luar daerah } \\
\text { karena kurangnya } \\
\text { waktu, biaya dan } \\
\text { tenaga. } \\
\text { Rasa tidak memiliki } \\
\text { madrasah. } \\
\text { Output tidak bisa } \\
\text { menciptakan kader- } \\
\text { kader baru } \\
\text { Keberatan wali murid } \\
\text { dengan penggabungan } \\
\text { biaya SPP. }\end{array}$ \\
\hline $\begin{array}{l}\text { Peluang (Opportunities) } \\
\text { - Banyaknya konsumen } \\
\text { yang tertarik dengan } \\
\text { MAA karena berbasis } \\
\text { pesantren }\end{array}$ & $\begin{array}{l}\text { SO Strategi } \\
\text { - MA Al Amiriyah dalam } \\
\text { memasarkan pendidikannya } \\
\text { memaksimalkan pemasaran } \\
\text { pendidikan di yayasan pondok }\end{array}$ & $\begin{array}{l}\text { WO Strategi } \\
\text { - Minat konsumen } \\
\text { semakin berkembang } \\
\text { untuk bergabung pada } \\
\text { lembaga MA Al }\end{array}$ \\
\hline
\end{tabular}

Strategi Pemasaran Pendidikan di MA Al Amiriyyah Blokagung Tegalsari Banyuwangi Mamlukhah, Faiz Inayah 


\begin{tabular}{|c|c|c|}
\hline 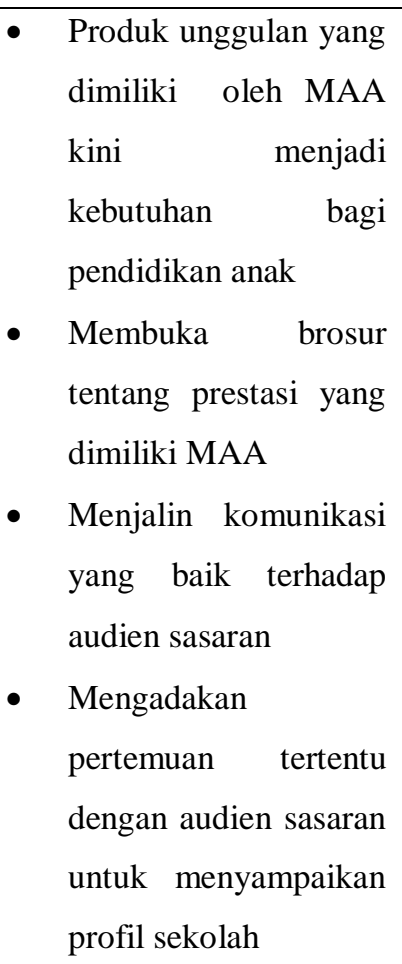 & $\begin{array}{l}\text { pesantren Darussalam } \\
\text { - Konsumen pendidikan diluar } \\
\text { yayasan pesantren } \\
\text { Darussalam dapat mengerti } \\
\text { tentang lembaga pendidikan } \\
\text { yang berbasis pesantren } \\
\text { - Memudahkan konsumen } \\
\text { pendidikan untuk } \\
\text { mendapatkan pendidikan yang } \\
\text { berbasis pesantren selain } \\
\text { pendidikan umum }\end{array}$ & $\begin{array}{l}\text { Amiriyyah } \\
\text { - Mendapatkan produk } \\
\text { unggulan tahfidz yang } \\
\text { ada di MA Al } \\
\text { Amiriyyah. }\end{array}$ \\
\hline 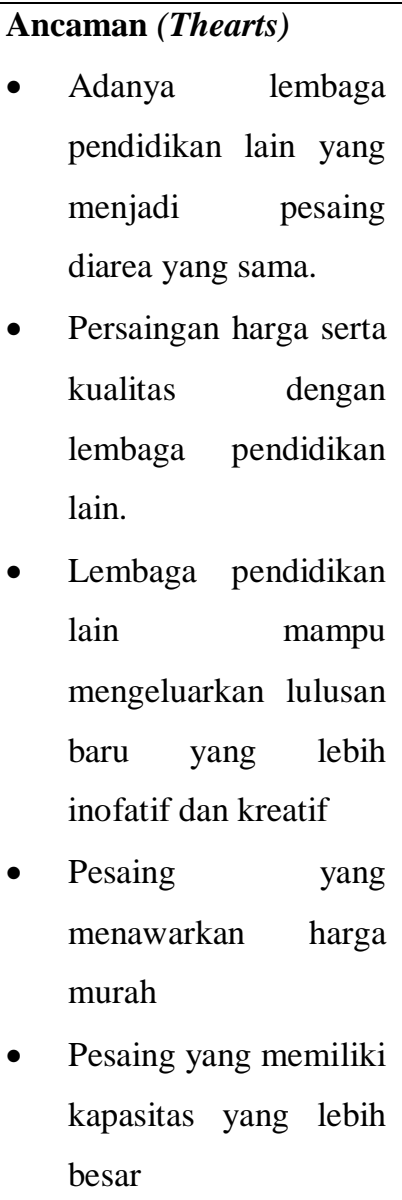 & 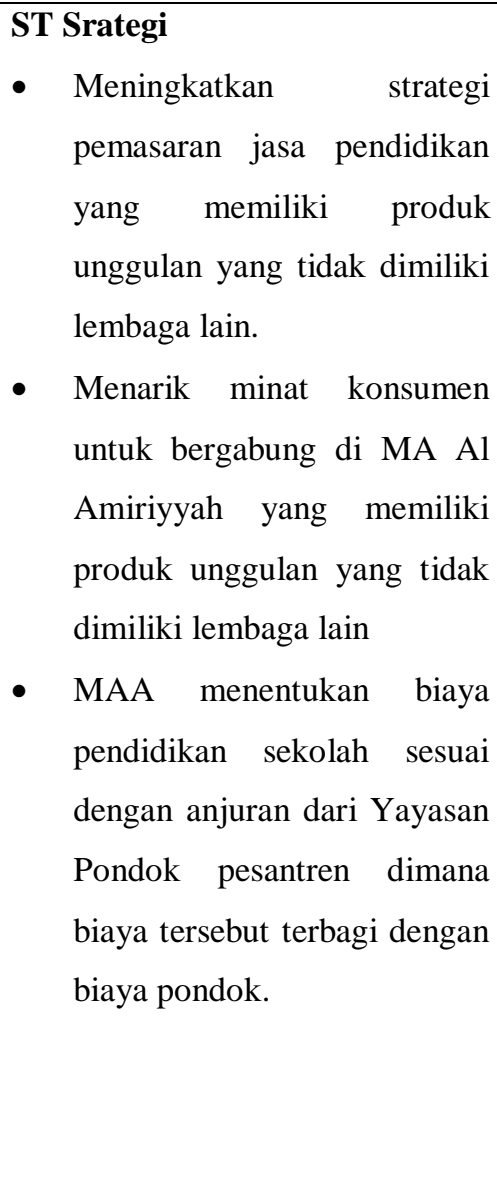 & $\begin{array}{l}\text { WT Strategi } \\
\text { Memprioritaskan } \\
\text { yayasan pondok } \\
\text { pesantren karena jumlah } \\
\text { siswa terbanyak yakni } \\
\text { dari santri. }\end{array}$ \\
\hline
\end{tabular}

Strategi Pemasaran Pendidikan di MA Al Amiriyyah Blokagung Tegalsari Banyuwangi 
Sumber: Data Olahan Peneliti (2020)

\section{Keterangan Tabel Penentuan Strategi Matrik IE (Internal Eksternal)}

Adapun keterangan tabel diatas meliputi penentuan strategi lingkungan internal dan eksternal yang ada di MA Al Amiriyyah blokagung banyuwangi diantaranya:

\section{Strategi SO (Strength-Opportunities)}

Berdasarkan tabel 3.4 dapat diketahui bahwa MA Al-Amiriyah memanfaatkan kekuatan yang ada dan memaksimalkan peluang yang di miliki oleh madrasah dalam memasarkan pendidikannya baik di lingkungan Yayasan Pondok Pesantren Darussalam dan diluar lingkungan Pondok Pesantren. Meskipun dalam prakteknya pemasaran pendidikan di lingkungan pondok pesantren menjadi prioritas yang utama. Hal ini dikarenakan mayoritas siswa/i nya merupakan santri pondok pesantren.

\section{Startegi ST (Strenghts-Threats)}

Berdasarkan tabel 3.4 dapat diketahui bahwasannya MA Al-Amiriyah menggunakan kekuatan yang dimiliki oleh madrasah untuk mengatasi ancaman yang terjadi dalam persaingan harga dengan lembaga pendidikan lain. Yang realitanya MA Al-Amiriyah menentukan biaya pendidikan sekolah sesuai dengan anjuran dari Yayasan Pondok pesantren dimana biaya tersebut terbagi dengan biaya pondok.

\section{Strategi WO (Weknesses- Opportunities)}

Berdasarkan tabel 3.4 dapat diketahui bahwasannya MA Al-Amiriyyah memanfaatkan peluang yang ada dan meminimalkan kelemahan khususnya dalam lingkup pesantren yang mana realitanya MA Al-Amiriyah ini memiliki produk unggulan tahfidz yang tidak dimiliki oleh lembaga lain dilingkup yang sama yakni pondok pesantren.

\section{Strategi WT (Weaknesses- Threats)}

Berdasarkan tabel 3.4 dapat diketahui bahwasannya MA Al-Amiriyyah berusaha meminimalkan kelemahan yang ada serta menghindari ancaman dengan tetap memprioritaskan yayasan pondok pesantren. 


\section{G. Kesimpulan}

\section{Strategi Pemasaran Pendidikan Di MA Al Amiriyyah Blokagung Banyuwangi.}

Strategi yang dilakukan di MA Al Amiriyyah yakni berupaya dalam meningkatkan strategi pemasaran di MA Al Amiriyyah biasanya menggunakan strategi promosi diantaranya:

a. Periklanan, seperti brosur sekolah, memasang spanduk, membentuk grup sekolah dalam akun sosial media, facebook wahtsapp, serta website.

b. Humas, di MA Al Amiriyyah melakukan promosi dengan cara berhubungan langsung dengan masyarakat, seperti mengadakan event tertentu, seperti pertemuan wali murid, haul, mengikuti olimpiade, mengadakan perlombaan ekstrakulikuler dengan kegiatan tersebut maka masyarakat akan lebih mengenal MA Al Amiriyyah, serta dapat menumbuhkan hubungan baik dengan berbagai masyarakat, serta orang tua siswa.

\section{Faktor Pendukung Dan Penghambat Dalam Strategi Pemasaran}

\section{Pendidikan Di MA Al Amiriyyah Blokagung Banyuwangi.}

a. Faktor pendukung dalam strategi pemasaran pendidikan di MA Al Amiriyyah, antara lain:

1) Tenaga pendidik yang mengajar di MA Al Amiriyyah mayoritas sudah sertifikasi dan mengajar sesuai bidangnya masing-masing.

2) Memiliki website sekolah yang digunakan untuk mempromosikan jasa pendidikan

3) Memiliki produk unggulan tahfidz yang jarang dimiliki oleh sekolah lain.

4) Menjalin hubungan baik dengan masyarakat, siswa, serta orang tua siswa dengan meningkatkan mutu dan pelayanan sekolah.

5) Letak sekolah yang strategis, serta sekolah yang berbasis pesantren.

b. Sedangkan faktor penghambat dalam strategi pemasaran di MA Al Amiriyyah sebagai berikut: 
1) Memiliki persaingan yang ketat, juga memiliki kekuatan yang hebat.

2) Adanya lembaga lain yang berada di area yang sama.

3) Terbatasnya anggaran biaya, waktu dan tenaga yang digunakan untuk program-progran pemasaran sekolah.

\section{H. Daftar Pustaka}

Amalia Lili. 2017. Strategi Pemasaran Jasa Pendidikan di SMP Harapan Baru Bekasi. Skripsi. Bekasi: Program Pasca Sarjana UIN Bekasi.

Arman Andri, “ Analisis Bauran Promosi Terhadap Keputusan Konsumen Membeli Sepeda Motor Merk Yamaha Pada Cv Sinar Utama Cabang Antasari Di Samarinda”. 3(3)

Ayu Famela Galesa. 2019. Implementasi Strategi Pemasaran Pendidikan, Bandar Lampung.

DH Basu Swasta. 1984. Azas-azas Marketing Yogyakarta: Liberty.

Etta Mamang S. \& Sopiah, 2013. Perilaku Konsumen Pendekatan Praktis, Yogyakarta: ADICITA GROUP

Fradito Aditia. 2016. Strategi Pemasaran Pendidikan Dalam Meningkatkan

Citra Lembaga Pendidikan. Skripsi. Malang: UIN Maulana Malik Ibrahim Malang.

KBBI. Kamus Besar Bahasa Indonesia (KBBI). 2005. Jakarta: Balai Pustaka

Khasanah, Afidatun. 2015. Jasa Pendidikan Sebagai Strategi Peningkatan Mutu di SD Alam Baturraden, Jurnal El-tarbawi, 8(2).

Moleong, Lex J. 2007. Metode Penelitian Kualitatif. Jakarta: PT. Remaja Rosdakarya.

Muhibbin Syah. 2005. Psikologi Pendidikan dengan Pendekatan Baru. Bandung: Remaja Rosda Karya, edisi revisi.

Nuary Nizar Sapta. 2016. Strategi Pemasaran Dengan Pendekatan Analisis Swot Pada PT. Kusumahadi Santosa Di Karanganyar (Studi Pada Divisi Pemasaran I Lokal Pada PT. Super Sukses Motor Banjarmasin. Jakarta: PT Gramedia Pustaka Utama. 
Philip Kotler \& Kevin Lane Keller. 2012. Marketing Management. New Jersey: Prentice.

Prawitasari Sri Yati, 2010. Analisis SWOT Sebagai Dasar Perumusan Strategi Pemasaran Berdaya Saing (Studi Pada Dealer Honda Tunggul Sakti Di Semarang).

Rachmat. 2014. Manajemen Strategik, Bandung: CV. Pustaka Setia.

Sofyan, Iban. 2015. Manajemen Strategi, Jakarta: Graha Ilmu. 